\title{
Improving insect conservation across heterogeneous landscapes using species-habitat networks
}

\author{
Andree Cappellari ${ }^{\text {Corresp., } 1}$, Lorenzo Marini ${ }^{1}$ \\ ${ }^{1}$ Department of Agronomy, Food, Natural resources, Animals and Environment (DAFNAE), University of Padua, Legnaro, Padua, Italy \\ Corresponding Author: Andree Cappellari \\ Email address: andree.cappellari@phd.unipd.it
}

Background. One of the biggest challenges in conservation is to manage multiple habitats for the effective conservation of multiple species, especially when the focal species are mobile and use multiple resources across heterogeneous protected areas. The application of ecological network tools and the analysis of the resulting species-habitat networks can help to describe such complex spatial associations and improve the conservation of species at the landscape scale.

Methods. To exemplify the application of species-habitat networks, we present a case study on butterflies inhabiting multiple grassland types across a heterogeneous protected area in North-East Italy. We sampled adult butterflies in 44 sites, each belonging to one of the five major habitat types in the protected area, i.e. disturbed grasslands, continuous grasslands, evolved grasslands, hay meadows and wet meadows. First, we applied traditional diversity analyses to explore butterfly species richness and evenness. Second, we built and analyzed both the unipartite network, linking habitat patches via shared species, and the bipartite network linking species to individual habitat patches.

Aims. (i) To describe the emerging properties (connectance, modularity, nestedness, and robustness) of the species-habitat network at the scale of the whole protected area, and (ii) to identify the key habitats patches for butterfly conservation across the protected area, i.e. those supporting the highest number of species and those with unique species assemblages (e.g. hosting specialist species).

Results. The species-habitat network appeared to have a weak modular structure, meaning that the main habitat types tended to host different species assemblages. However, the habitats also shared a large proportion of species that were able to visit multiple habitats and use resources across the whole study area. Even butterfly species typically considered as habitat specialists were actually observed across multiple habitat patches, suggesting that protecting them only within their focal habitat might be ineffective. Our species-habitat network approach helped identifying both central habitat patches that were able to support the highest number of species, and habitat patches that supported rare specialist species. 


\section{Improving insect conservation across heterogeneous} 2 landscapes using species-habitat networks

3

4 Andree Cappellari ${ }^{1}$, Lorenzo Marini $^{1}$

5

$6 \quad{ }^{1}$ Department of Agronomy, Food, Natural resources, Animals and Environment (DAFNAE),

7 University of Padua, Legnaro, Padua, Italy

8

9 Corresponding Author: Andree Cappellari ${ }^{1}$

10 Email address: andree.cappellari@phd.unipd.it 


\section{Abstract}

12 Background. One of the biggest challenges in conservation is to manage multiple habitats for the effective conservation of multiple species, especially when the focal species are mobile and use multiple resources across heterogeneous protected areas. The application of ecological network tools and the analysis of the resulting species-habitat networks can help to describe such complex spatial associations and improve the conservation of species at the landscape scale. Methods. To exemplify the application of species-habitat networks, we present a case study on butterflies inhabiting multiple grassland types across a heterogeneous protected area in NorthEast Italy. We sampled adult butterflies in 44 sites, each belonging to one of the five major habitat types in the protected area, i.e. disturbed grasslands, continuous grasslands, evolved grasslands, hay meadows and wet meadows. First, we applied traditional diversity analyses to explore butterfly species richness and evenness. Second, we built and analyzed both the unipartite network, linking habitat patches via shared species, and the bipartite network, linking species to individual habitat patches.

Aims. (i) To describe the emerging properties (connectance, modularity, nestedness, and robustness) of the species-habitat network at the scale of the whole protected area, and (ii) to identify the key habitats patches for butterfly conservation across the protected area, i.e. those supporting the highest number of species and those with unique species assemblages (e.g. hosting specialist species).

Results. The species-habitat network appeared to have a weak modular structure, meaning that the main habitat types tended to host different species assemblages. However, the habitats also shared a large proportion of species that were able to visit multiple habitats and use resources across the whole study area. Even butterfly species typically considered as habitat specialists were actually observed across multiple habitat patches, suggesting that protecting them only within their focal habitat might be ineffective. Our species-habitat network approach helped identifying both central habitat patches that were able to support the highest number of species, and habitat patches that supported rare specialist species.

\section{Introduction}

Protected areas play a fundamental role for the conservation of biodiversity. In many cases, however, these areas are composed of a mosaics of small patches of different habitat types, both managed and unmanaged ones. The conservation of insect diversity across such heterogeneous landscapes may face various problems, in particular when the focal species are mobile and use multiple resources across different habitat patches (Kremen et al., 2007; Marini et al., 2019). For instance, when landscapes are composed of small patches with a large perimeter-to-area ratio, the local communities are heavily impacted by the surrounding landscape (Krauss, SteffanDewenter \& Tscharntke, 2003). Most of the decisions on how to manage single habitats for conservation are usually based on the results of diversity analyses where patches, habitats or interventions are usually ranked according to the number of species and individuals they support (see for example Villemey et al., 2015; Ernst, Tscharntke \& Batáry, 2017; Denning \& Foster, 
51

52

53

54

55

56

57

58

59

60

61

62

63

64

65

66

67

68

69

70

71

72

73

74

75

76

77

78

79

80

81

82

83

84

85

86

87

88

89

90

2018). While this approach can help identifying ideal local habitat quality to maximize species diversity, it also overlooks the potential interactions between multiple habitat patches in supporting communities of mobile organisms (Harlio et al., 2019). There have been several attempts to implement landscape-scale approaches to conservation encouraging bigger and larger number of protected areas, enhancing connectivity, and improving habitat quality (Albert et al., 2017; Donaldson, Wilson \& Maclean, 2017), but little emphasis has been placed to develop tools to optimize conservation actions within protected areas characterized by large landscape heterogeneity at small spatial scale.

Managing multiple habitats for the conservation of multiple species can be challenging. Recently, it has been proposed to adapt network tools to describe such complex spatial interactions (Hackett et al., 2019; Marini et al., 2019) and to use the resulting species-habitat networks and their metrics to improve conservation of species at the landscape scale (Nardi et al., 2019; Pompozzi et al., 2019; Saunders \& Rader, 2019; Lami et al., 2020). First, topology metrics can inform on the architecture and the emerging properties of the whole species-habitat network. On the one hand, in a protected area with a nested structure species-rich patches host both common and rare species, while species-poor patches are mainly visited by generalist species and so their loss is unlikely to have ripple effects on the entire protected area (Table 1 a) (Patterson, 1987). On the other hand, in a protected area with a strong modular structure some species interact more frequently with some habitat types forming modules, so patches belonging to the same module are more tightly connected to each other than to patches belonging to different habitat types (Table $1 \mathrm{~b}$ ). In this scenario, different modules need to be considered as individual management blocks. Second, node-level metrics can describe properties of single habitat patches within the network. For instance, patch centrality can inform about the importance of single habitats and patches in supporting species across the whole protected area. A patch with high centrality hosts many species that also occur in other habitats, playing a fundamental role in supporting generalist species across the whole species-habitat network (Table $1 \mathrm{c}$ ).

To exemplify the application of species-habitat networks to inform landscape management, we present a case study on the conservation of butterflies across a heterogeneous protected area in North-East Italy. We selected butterflies as model organisms as they are excellent indicators of habitat quality, being particularly sensitive to environmental changes (Thomas et al., 2004; WallisDeVries \& Ens, 2010). Moreover, butterfly species largely vary in their life history traits such as mobility and phagy (Dennis, Shreeve \& Van Dyck, 2003). The chosen protected area is composed of five major habitat types intermixed across the area, i.e. three successional stages of dry calcareous grasslands along a natural disturbance gradient, that are usually the focus of conservation plans, and two managed grasslands, hay meadows and wet meadows, that can be seen as potential surrogate habitats to support butterfly diversity. We first applied traditional diversity analyses and then focused on unipartite and bipartite species-habitat network analyses. The aims of this study were: (i) to describe the emerging properties of the species-habitat network at the scale of the whole protected area, and (ii) to identify the key 
91 habitat patches for butterfly conservation across the protected areas, i.e. those supporting the 92 highest number of species and those with unique species assemblages (e.g. hosting specialist 93 species). The information derived will help to tailor management plan for the protected area.

94

95

96

97

98

99

100

101

102

103

104

105

106

107

108

109

110

111

112

113

114

115

116

117

118

119

120

121

122

123

124

125

126

127

128

129

\section{Materials \& Methods}

\section{Study area}

The study was carried out in the Friuli-Venezia Giulia region (North-East Italy), in the Special Protection Area "Magredi di Pordenone" (SPA-IT 33110011) (4604'12.5" N 1245'46.5" E). The area is part of the European Union Natura 2000 network, the largest coordinated system of protected areas in the world, covering over $18 \%$ of the EU land area. The size of the chosen protected area is c. $101 \mathrm{~km}^{2}$, and it includes four Sites of Community Importance: "Magredi di Tauriano" (SIC-IT3310008), "Magredi del Cellina" (SIC-IT 3310009), "Torbiera di Sequals" (SIC-IT 3310005) and "Risorgive del Vinchiaruzzo" (SIC-IT3310010). The bedrock consists of coarse alluvial calcareous-dolomitic sediments. The area is protected by the Natura 2000 network for its high value ecosystems (LIFE10 NAT/IT/000243), and it is characterized by a remarkable diversity of alluvial grassland habitats. We identified five main habitat types: three successional stages of dry semi-natural grasslands on calcareous substrate along a disturbance gradient, i.e. (i) recently disturbed grasslands, with a low herbaceous cover (bare ground cover $>$ $75 \%$ ) and mainly composed by pioneer species, (ii) continuous grasslands, with intermediate natural disturbance, and a moderate herbaceous cover $(10 \%<$ bare ground cover $<30 \%)$, and (iii) evolved grasslands, undisturbed for long time, and with a continuous herbaceous cover (bare ground cover $<10 \%$ ) and presence of isolated shrubs; and two managed grasslands, i.e. (iv) hay meadows, un-improved grassland mown twice a year and (v) wet meadows, mown once every 12 years (Table S1). The natural disturbance in dry calcareous grasslands is related to periodic floods that destroy the vegetation and the organic layer of the soil, halting the shrub encroachment. The continuous and evolved semi-natural dry grasslands are classified as Natura 2000 habitat $62 \mathrm{~A} 0$ (Eastern sub-Mediterranean dry grasslands, Scorzoneretalia villosae).

\section{Sampling design and butterfly sampling}

We selected 44 sites, each belonging to one habitat type (Fig. S1). The number of sites for each habitat type was proportional to their cover in the protected area. We therefore selected 10 patches for each successional grassland stage and 7 patches for both hay meadows and wet meadows. Each site covered an area of $2500 \mathrm{~m}^{2}(50 \times 50 \mathrm{~m})$. Adult butterflies (Papilionoidea) were surveyed five times between March and September 2010. Sampling occurred between 09.00 and 17.00 in days with favorable weather conditions (cloudiness $<25 \%$, low or absent wind, air temperature $>18^{\circ} \mathrm{C}$ ). Each site was sampled for 15 minutes for each round. Surveys were always carried out by the same two operators, LM and Paolo Paolucci (University of Padua), which recorded all butterflies in the sampling area by visual sighting. Individuals that could not be identified while in flight were caught, identified and released at the end of the sampling. In each round, the order in which sites were sampled was 
130 randomized to avoid bias related to the time of sampling. Butterfly nomenclature follows

131 Karsholt \& Nieukerken (2011).

\section{Data analyses}

\section{Diversity analyses}

134 For each habitat patch, we calculated butterfly richness (total number of species) and evenness

$135\left(\mathrm{E}_{\mathrm{var}}\right.$ index $)$ and used linear models to evaluate the effect of the habitat type on diversity indices.

136 Both indices were calculated using the vegan package (Oksanen et al., 2019). All analyses were

137 performed using R version 3.6.1 (R Development Core Team, 2019).

138 Species-habitat network analyses: bipartite network

139 We built a bipartite weighted network with patches and butterfly species as nodes, and calculated

140 four network-level metrics providing complementary and non-redundant information:

141 modularity, weighted NODF, robustness and connectance. Modularity describes how interactions

142 between butterflies and patches are partitioned into separate modules, ranging between 0

143 (random network) and 1 (complete compartmentalized network) (Newman, 2006). Weighted

144 NODF, the weighted Nestedness metric based on Overlap and Decreasing Fill, is the property by

145 which specialist species interact with a subset of the sites that generalist species interact with,

146 ranging between 0 (non-nested network) and 100 (perfectly nested network) (Almeida-Neto \&

147 Ulrich, 2011). We then checked for both metric significance using z-scores, calculated using

1481000 null models obtained with the Patefield algorithm (Dormann \& Strauss, 2014). The two

149 metrics provide fundamental information about network architecture (Bascompte et al., 2003;

150 Olesen et al., 2007; Bastolla et al., 2009; Thébault \& Fontaine, 2010; Tylianakis et al., 2010;

151 Carstensen, Sabatino \& Morellato, 2016; Grilli, Rogers \& Allesina, 2016). Robustness, a

152 measure of network stability against species extinction, was calculated removing butterfly

153 species from the network from the rarest to the most abundant, ranging between 0 (highly

154 unstable network) and 1 (highly stable network) (Memmott, Waser \& Price, 2004). Connectance

155 is a measure of network complexity which specifies the realized proportion of all possible links

156 in a network, ranging between 0 (simple network) and 1 (complex network) (Dunne, Williams \&

157 Martinez, 2002). To compute network-level metrics, we used the bipartite package (Dormann,

158 Gruber \& Fründ, 2008).

159 Species-habitat network analyses: unipartite network

160 Starting from the bipartite species-habitat network, we built a unipartite weighted network, with

161 patches as nodes and shared butterfly species as edges, i.e. links between nodes. The weight of

162 these links reflects the number of shared butterfly species between sites. Unipartite networks

163 provide complementary information on network topology and node role in the network by using

164 centrality metrics and community detection techniques developed for studying social networks

165 (Freeman, 1978; Borgatti, 2015; Bedi \& Sharma, 2016).

166

167

For each patch, we calculated weighted degree centrality, an index which specifies the

168 role played by each patch within the network, highlighting the focal ones. It is based on both the

169 number of connections with other patches and the average weight of these connections, adjusted by an $\alpha$ parameter (Opsahl, Agneessens \& Skvoretz, 2010). We set the $\alpha$ parameter to 0.5, so 
170 patches with a higher number of connections have a stronger weighted degree centrality value

171 (Rodríguez-Rodríguez, Jordano \& Valido, 2017). A high centrality value indicates a patch which

172 hosts many generalist species, while a low centrality value indicates a patch which hosts

173 specialist or few species. We then used linear models to test the effect of habitat type on patch

174 weighted degree centrality.

175 Moreover, to further investigate the structure of butterfly communities, we applied

176 several community detection techniques. Community detection analysis is similar to modularity

177 analysis in a bipartite network, but it is based on unipartite networks, so the result is a

178 clusterization of patches based on the butterfly species they share. Because of the small network

179 size (44 sites $\times 74$ butterfly species) and the high value of the mixing parameter $\mu$ calculated

180 using the multimodel algorithm $(\mu=0.58)$, we selected two more algorithms for detecting

181 communities, the spinglass algorithm and the walktrap algorithm (Yang, Algesheimer \&

182 Tessone, 2016).

183 We used the igraph package (Csardi \& Nepusz, 2006) for building the unipartite

184 weighted network and for community detection analysis, while weighted degree centrality was

185 calculated using the tnet package (Opsahl, 2015).

186

187

\section{Results}

188

In the 44 sites, we sampled 6,273 butterflies belonging to 74 species and 5 families (Table S2).

189

190

The most abundant species were Coenonympha pamphilus (1022 individuals), Melanargia

191

galathea (711 individuals) and Coenonympha arcania (491 individuals), while the most frequent ones were Pieris rapae (found in 32 sites), Coenonympha pamphilus (found in 31 sites) and

192 Polyommatus icarus (found in 28 sites) (Table S2). We sampled two species included in the Habitats Directive annexes II and IV, Coenonympha oedippus (17 individuals in one site) and

194 Lycaena dispar (11 individuals in one site), one species that is categorized as vulnerable in the Italian Red List for butterflies, Phengaris alcon (1 individual) (Bonelli et al., 2018) and one species that is protected in the Friuli Venezia-Giulia region, Thecla betulae (2 individuals in one site) (Valenti \& Renzi, 2016) (Table S2). In each site, we found an average of 143 individuals $(\min =2, \max =435)$ and an average of 17 butterfly species $(\min =1, \max =32)($ Table S3). The poorest habitat in terms of both butterfly abundance and richness was the disturbed grassland,

200 with a total of 68 individuals belonging to 10 species. The richest one was the evolved grassland,

201

202 with a total of 2655 individuals belonging to 54 species (Table S3).

203

204

205

206

207

208

209

\section{Whole network}

The species-habitat network was complex, with highly connected habitat patches and butterfly species (connectance $=0.28$ ), even if its size was relatively small (44 habitat patches $\mathrm{x} 74$ butterfly species) (Fig. 1), so network structure was highly stable (robustness $=0.96$ ). The network was significantly more modular than expected by chance (modularity $=0.35$, modularity $z$-score $=95$ ), and clusters coarsely matched habitat types, at least for the managed ones (Fig. S2). The modularity value, however, indicated a weak modular structure. On the other hand, the network was less nested than expected from the null models (weighted NODF $=25.04$, weighted

Peer) reviewing PDF | (2020:08:52268:1:1:NEW 2 Nov 2020) 
210 NODF z-score $=-28.8$ ). Community detection analysis confirmed the weighted NODF and 211 modularity results. Both the multilevel and spinglass algorithms identified three communities 212 (Figs. 2 a-b), while the walktrap algorithm identified four communities (Fig. 2 c). In general, the 213 results of the three community detection algorithms converged and identified similar clusters. 214 We can recognize three major communities: one for disturbed dry calcareous grasslands, one for 215 un-managed grasslands (continuous and evolved dry calcareous grasslands) and one for managed 216 grasslands (hay and wet meadows).

\section{Habitat level}

218 Species richness, species evenness $\mathrm{E}_{\mathrm{var}}$, and patch weighted degree centrality were strongly 219 related to habitat type (Figs. 3 a-c, Table 2). Disturbed grassland was the habitat with the lower 220 species richness and centrality values, and the higher evenness. The number of butterfly species 221 and the patch centrality values strongly increased along the grassland successional gradient, 222 while evenness exhibited an opposite pattern. All three indices were comparable for evolved 223 grassland and hay meadow, while only species evenness was similar for evolved grassland and 224 continuous grassland.

225 Patch level

226 Weighted degree centrality for patches was moderately high, with a mean value of $102.38(\mathrm{~min}=$ $22725, \max =150.39$ ), because of the high number of connections between habitat patches. The 228 ranking of patches based on their centrality values showed that the most central patches did not 229 belong to a single habitat (Figs. $4 \mathrm{a}$-b). In fact, the ten most central patches belonged to all 230 habitat types except for disturbed grassland: four hay meadow patches, three evolved grassland 231 patches, two continuous grassland patches, and one wet meadow patch. All disturbed grassland 232 patches were peripherals. Species richness and evenness were strongly correlated to weighted 233 degree centrality (Pearson's correlation for patch centrality and species richness $=0.95, \mathrm{p}$-value $234<0.01$; Pearson's correlation for patch centrality and species evenness $=-0.87$, $\mathrm{p}$-value $<0.01$ ), 235 so the most central patches hosted more species and their abundance distribution was more 236 uneven.

\section{Discussion}

239 Here, we proposed to adapt ecological network tools to describe complex spatial interactions 240 between species and habitats (Marini et al., 2019) and to use the resulting network metrics to 241 improve conservation of butterfly species across a heterogeneous protected area. Despite the 242 small size of the protected area, we found a remarkable diversity of butterflies, with 74 species, 243 more than $25 \%$ of the total butterfly richness of Italy (Bonelli et al., 2018). The species-habitat 244 network highlighted a general relaxed specialization of butterflies for habitats, indicating that 245 species were affected by the management of the whole protected areas, beyond the boundaries of 246 their preferred habitat type. The species-habitat network approach helped identifying both 247 central habitat patches that were able to support the highest number of species and also habitat 248 modules that supported rare specialist species.

\section{Whole network}


250 Network-level metrics can help to unveil the emergent properties of species-habitat networks. 251 Modularity in bipartite networks plays an important role in network function, often improving 252 community stability (Olesen et al., 2007; Tscharntke et al., 2007; Tylianakis et al., 2010; Grilli, 253 Rogers \& Allesina, 2016). In species-habitat networks, modules are composed of groups of 254 tightly interacting species and patches. In our network, modularity was higher than expected by 255 chance, and modules coarsely matched major habitat types. However, modularity was generally

256

257

258

259

260

261

262

263

264

265

266

267

268

269

270

271

272

273

274

275

276

277

278

279

280

281

282

283

284

285

286

287

288

289 weak, indicating that several modules were still highly connected to each other. In particular, some habitats - the continuous and evolved grasslands - were visited by many species, and those species were mainly generalists. On the other hand, in our modularity analysis based on bipartite networks, four out of seven patches of wet meadow created a single, strong module due to the presence of specialist species such as Coenonympha oedippus and Lycaena dispar (Skórka, Settele \& Woyciechowski, 2007). The removal of the wetland patches can therefore strongly affect the butterfly species pool of the whole protected area, being harmful for the persistence of rare, specialist species. The whole network, overall, was highly stable in terms of robustness to species extinction, as even specialist species were hosted in several habitat patches.

Differences in species assemblages between habitat types were confirmed by the community detection analysis. All detection algorithms yielded similar results and patches belonging to the same habitat almost always clustered together. The first community was roughly composed of only disturbed grassland patches, the second one was composed of calcareous dry habitat patches (continuous and evolved grassland) and the third one was composed of managed habitat patches (hay and wet meadows). It is therefore important to notice that community detection analysis, as all techniques that rely on unipartite networks, is exclusively based on shared species, and does not take into account the unshared ones, while modularity based on bipartite networks can identify key habitat patches for specialist species. For conservation purposes, it is therefore fundamental to apply both approaches to capture different facets of network organization. While modularity allowed to identify groups of patches where specialists are concentrated, centrality helped to identify the habitat patches that supported a larger number of generalists. Depending on the conservation aims, actions could focus on specific habitat patches or, on the contrary, manage the protected area as a whole, considering all habitat patches together.

\section{Habitat level}

Species richness, evenness and patch centrality differed among habitats. Disturbed grasslands had the lowest species richness and patch centrality, and the highest species evenness. The low herbaceous cover, low diversity of plant species and low flower availability of disturbed grasslands led to species-poor communities with even abundance distribution. The high evenness in disturbed grasslands was probably driven by the immigration of mobile and generalist species and by the low contribution to density from local recruitment (Marini et al., 2014). As the succession of grassland ecosystems proceeded, plant cover, plant richness and therefore butterfly species richness and patch centrality increased, with a consequent decrease in species evenness. Evolved grasslands were the most central habitat due to their considerable diversity of plant species and complex vegetation structure including both herbaceous species and shrubs 
290 (WallisDeVries, Poschold \& Willems, 2002; Ernst, Tscharntke \& Batáry, 2017). Hay meadows, 291 despite being impacted by mowing, hosted many species and were as central as evolved 292 grasslands. The positive impact of low-intensity management on plant and butterfly communities 293 has already been investigated (WallisDeVries \& Raemakers, 2001; Silva et al., 2019), and a 294 mosaic of managed and un-managed patches seems to be the best solution for maintaining 295 biodiversity and network robustness. In fact, managed meadows are located in sites where 296 floods, quite common in the study area, do not occur, safeguarding habitat patches suitable for a 297 large number of butterfly species. The absence of flood disturbance is therefore a key driver of 298 butterfly species diversity in hay meadows, despite the local disturbance of mowing. The central 299 role of managed meadows also suggests that this habitat can contribute to increase the area of 300 suitable habitat for the large majority of butterfly species considered typical of dry calcareous 301 grasslands.

\section{Patch level}

303 Planning of conservation actions in protected areas often requires information about the role of

304

305

306

307

308

309

310

311

312

313

314

315

316

317

318

319

320

321

322

323

324

325

326

327

328

single sites in supporting the focal biodiversity groups. The use of centrality measures to rank the importance of single patches has been extensively studied (Estrada \& Bodin, 2008; Gilarranz et al., 2015; Poodat et al., 2015; Pereira, Saura \& Jordán, 2017), as central nodes are known to promote stability in habitat networks (Thompson, Rayfield \& Gonzalez, 2017). As explained above, evolved grasslands and hay meadows turned out to be fundamental habitats for butterfly conservation, but the ranking of individual patches based on weighted degree centrality also showed that central patches did not exclusively belong to these habitats. Furthermore, even within the same habitat, not all patches were equally relevant. This indicates that some patches can play an important role in the protected area irrespective of the habitat type. The most peripheral nodes were represented by both disturbed grassland and wet meadow patches, but while disturbed grasslands were always characterized by species-poor communities, wet meadows were rich in specialist species that were not shared with other habitats. As evolved grassland and hay meadow patches had a similar role in supporting butterfly communities within the protected area, several managed meadow patches can be seen as a surrogate habitat for dry semi-natural grasslands in supporting a large number of shared species. Centrality analysis can therefore be a useful tool to highlight the focal patches within a heterogeneous landscape and so to improve conservation planning.

\section{Study limitations}

There are two main limitations of this study. First, even if most butterflies were counted while foraging on flowers, some individuals were possibly using habitat patches only as stepping stones for dispersal. Traditional butterfly transect counts should therefore be complemented with more detailed information on how individuals interact with local resources. Second, our network analyses on modularity and community detection are not spatially explicit. Besides the habitat similarity effects, other drivers can contribute to form habitat modules across species-habitat networks. In particular, spatial autocorrelation can be an important process as habitat distribution 
329

330

331

332

333

334

335

336

337

338

339

340

341

342

343

344

345

346

347

348

349

350

351

352

353

across real landscapes is often non-random making difficult to disentangle pure habitat from pure spatial effects.

\section{Conclusions}

Developing conservation plans for protected areas across heterogeneous landscapes can be difficult. Here, we highlight the importance of an integrative approach, combining traditional diversity analysis and network analysis, for the identification of focal habitats and patches in a protected area. The species-habitat network of the protected area appeared to have a weak modular structure where the main habitat types tended to host different species assemblages. However, the habitat modules also shared a large proportion of species that are able to move and use resources across the whole protected area. Even butterfly species typically considered as habitat specialists according to the literature were actually observed across several habitats, suggesting that protecting them only within their focal habitat can be limiting. Calcareous dry grasslands are well-known key habitats for butterfly conservation (Silva et al., 2019), but we also pointed out the central role of agriculturally managed meadows across the protected area. Hay meadows, in particular, can act as a surrogate habitat for evolved calcareous grasslands patches, hosting surprisingly similar species assemblages. Although hay meadows are not currently considered as habitats with high conservation priority, more attention should be placed on the maintenance of their extensive management. Wet meadows emerged as the only habitats characterized by a distinctive module of wetland specialists. In conclusion, the protected area needs to be considered as a single dynamic unit to plan conservation actions.

\section{Acknowledgements}

We thank Paolo Paolucci, Alessandro Fracasso and Luvi Dal Canton for their help during the field work. 


\section{References}

355 Albert CH, Rayfield B, Dumitru M, Gonzalez A. 2017. Applying network theory to prioritize 356 multispecies habitat networks that are robust to climate and land-use change. Conservation 357 Biology 31:1383-1396. DOI: 10.1111/cobi.12943.

358 Almeida-Neto M, Ulrich W. 2011. A straightforward computational approach for measuring 359 nestedness using quantitative matrices. Environmental Modelling and Software 26:173-178.

360 DOI: 10.1016/j.envsoft.2010.08.003.

361 Bascompte J, Jordano P, Melián CJ, Olesen JM. 2003. The nested assembly of plant-animal 362 mutualistic networks. Proceedings of the National Academy of Sciences of the United States of 363 America 100:9383-9387. DOI: 10.1073/pnas.1633576100.

364 Bastolla U, Fortuna MA, Pascual-García A, Ferrera A, Luque B, Bascompte J. 2009. The 365 architecture of mutualistic networks minimizes competition and increases biodiversity. Nature 366 458:1018-1020. DOI: 10.1038/nature07950.

367 Bedi P, Sharma C. 2016. Community detection in social networks. WIREs Data Mining and 368 Knowledge Discovery 6: 115-135. DOI: 10.1002/widm.1178.

369 Bonelli S, Casacci LP, Barbero F, Cerrato C, Dapporto L, Sbordoni V, Scalercio S, Zilli A, 370 Battistoni A, Teofili C, Rondinini C, Balletto E. 2018. The first red list of Italian butterflies. 371 Insect Conservation and Diversity 11:506-521. DOI: 10.1111/icad.12293.

372 Borgatti, SP. 2015. Centrality and network flow. Social Networks 27: 55-71. DOI:

373 10.1016/j.socnet.2004.11.008.

374 Carstensen DW, Sabatino M, Morellato LPC. 2016. Modularity, pollination systems, and

375 interaction turnover in plant-pollinator networks across space. Ecology 97:1298-1306. DOI:

376 10.1890/15-0830.1.

377 Csardi G, Nepusz T. 2006. The igraph software package for complex network research.

378 InterJournal Complex Systems. http://igraph.org.

379 Denning KR, Foster BL. 2018. Taxon-specific associations of tallgrass prairie flower visitors 380 with site-scale forb communities and landscape composition and configuration. Biological 381 Conservation 227:74-81. DOI: 10.1016/j.biocon.2018.08.023.

382 Dennis RLH, Shreeve TG, Van Dyck H. 2003. Towards a functional resource-based concept for 383 habitat: A butterfly biology viewpoint. Oikos 102:417-426. DOI: 10.1034/j.1600-

384 0579.2003.12492.x.

385 Donaldson L, Wilson RJ, Maclean IMD. 2017. Old concepts, new challenges: adapting

386 landscape-scale conservation to the twenty-first century. Biodiversity and Conservation 26:527387 552. DOI: 10.1007/s10531-016-1257-9.

388 Dormann CF, Strauss R. 2014. A method for detecting modules in quantitative bipartite 389 networks. Methods in Ecology and Evolution 5:90-98. DOI: 10.1111/2041-210X.12139. 390 Dormann C, Gruber B, Fründ J. 2008. Introducing the bipartite Package: Analysing Ecological 391 Networks. R news 8:8-11. 
392 Dunne JA, Williams RJ, Martinez ND. 2002. Food-web structure and network theory: The role 393 of connectance and size. Proceedings of the National Academy of Sciences of the United States 394 of America 99:12917-12922. DOI: 10.1073/pnas.192407699.

395 Ernst LM, Tscharntke T, Batáry P. 2017. Grassland management in agricultural vs. forested 396 landscapes drives butterfly and bird diversity. Biological Conservation 216:51-59. DOI: 397 10.1016/j.biocon.2017.09.027.

398 Estrada E, Bodin Ö. 2008. Using network centrality measures to manage landscape connectivity. 399 Ecological Applications 18:1810-1825. DOI: 10.1890/07-1419.1.

400 Freeman LC. 1978. Centrality in social networks conceptual clarification. Social Networks 1:

401 215-216. DOI: 10.1016/0378-8733(78)90021-7.

402 Gilarranz LJ, Sabatino M, Aizen MA, Bascompte J. 2015. Hot spots of mutualistic networks. 403 Journal of Animal Ecology 84:407-413. DOI: 10.1111/1365-2656.12304.

404 Grilli J, Rogers T, Allesina S. 2016. Modularity and stability in ecological communities. Nature 405 Communications 7. DOI: 10.1038/ncomms12031.

406 Hackett TD, Sauve AMC, Davies N, Montoya D, Tylianakis JM, Memmott J. 2019. Reshaping 407 our understanding of species' roles in landscape-scale networks. Ecology Letters 22:1367-1377. 408 DOI: $10.1111 /$ ele.13292.

409 Harlio A, Kuussaari M, Heikkinen RK, Arponen A. 2019. Incorporating landscape heterogeneity 410 into multi-objective spatial planning improves biodiversity conservation of semi-natural 411 grasslands. Journal for Nature Conservation 49:37-44. DOI: 10.1016/j.jnc.2019.01.003.

412 Karsholt O, Nieukerken EV. 2011. Lepidoptera. Fauna Europaea version 2.4.

413 http://www.faunaeur.org.

414 Krauss J, Steffan-Dewenter I, Tscharntke T. 2003. How does landscape context contribute to 415 effects of habitat fragmentation on diversity and population density of butterflies? Journal of 416 Biogeography 30:889-900. DOI: 10.1046/j.1365-2699.2003.00878.x.

417 Kremen C, Williams NM, Aizen MA, Gemmill-Herren B, LeBuhn G, Minckley R, Packer L, 418 Potts SG, Roulston T, Steffan-Dewenter I, Vázquez DP, Winfree R, Adams L, Crone EE, 419 Greenleaf SS, Keitt TH, Klein AM, Regetz J, Ricketts TH. 2007. Pollination and other 420 ecosystem services produced by mobile organisms: A conceptual framework for the effects of 421 land-use change. Ecology Letters 10:299-314. DOI: 10.1111/j.1461-0248.2007.01018.x.

422 Lami F, Bartomeus I, Nardi D, Beduschi T, Boscutti F, Pantini P, Santoiemma G, Scherber C, 423 Tscharntke T, Marini L. 2020- Species-habitat networks elucidate landscape effects on habitat 424 specialization of natural enemies and pollinators. Ecology Letters. DOI: 10.1111/ELE13642.

425 Marini L, Bartomeus I, Rader R, Lami F. 2019. Species-habitat networks: A tool to improve 426 landscape management for conservation. Journal of Applied Ecology 56:923-928. DOI:

$427 \quad 10.1111 / 1365-2664.13337$.

428 Marini L, Öckinger E, Bergman KO, Jauker B, Krauss J, Kuussaari M, Pöyry J, Smith HG, 429 Steffan-Dewenter I, Bommarco R. 2014. Contrasting effects of habitat area and connectivity on 430 evenness of pollinator communities. Ecography 37:544-551. DOI: $10.1111 / \mathrm{j} .1600-$ 431 0587.2013.00369.x. 
432 Memmott J, Waser NM, Price MV. 2004. Tolerance of pollination networks to species

433 extinctions. Proceedings of the Royal Society B 271:2605-2611. DOI: 10.1098/rspb.2004.2909.

434 Nardi D, Lami F, Pantini P, Marini L. 2019. Using species-habitat networks to inform

435 agricultural landscape management for spiders. Biological Conservation 239:108275. DOI:

$436 \quad 10.1016 /$ j.biocon.2019.108275.

437 Newman MEJ. 2006. Modularity and community structure in networks. Network Science

438 103:8577-8582. DOI: 10.1017/nws.2015.20.

439 Oksanen AJ, Blanchet FG, Friendly M, Kindt R, Legendre P, Mcglinn D, Minchin PR, Hara

440 RBO, Simpson GL, Solymos P, Stevens MHH, Szoecs E. 2019. vegan: Community Ecology

441 Package. R package version 2.5-6. https://CRAN.R-project.org/package=vegan.

442 Olesen JM, Bascompte J, Dupont YL, Jordano P. 2007. The modularity of pollination networks.

443 Proceedings of the National Academy of Sciences 104:19891-19896. DOI:

444 10.1073/pnas.0706375104.

445 Opsahl T. 2015. Package "tnet": Software for analysis of weighted, two-mode, and longitudinal 446 networks.

447 Opsahl T, Agneessens F, Skvoretz J. 2010. Node centrality in weighted networks: Generalizing 448 degree and shortest paths. Social Networks 32:245-251. DOI: 10.1016/j.socnet.2010.03.006.

449 Patterson BD. 1987. The principle of nested subsets and its implications for biological

450 conservation. Conservation Biology 1:323-334. DOI: https://www.jstor.org/stable/2386017.

451 Pereira J, Saura S, Jordán F. 2017. Single-node vs. multi-node centrality in landscape graph

452 analysis: key habitat patches and their protection for 20 bird species in NE Spain. Methods in

453 Ecology and Evolution 8:1458-1467. DOI: 10.1111/2041-210X.12783.

454 Pompozzi G, Marrero HJ, Haedo J, Fritz L, Torretta JP. 2019. Non-cropped fragments as

455 important spider reservoirs in a Pampean agro-ecosystem. Annals of Applied Biology 175:326-

456 335. DOI: 10.1111/aab.12537.

457 Poodat F, Arrowsmith C, Fraser D, Gordon A. 2015. Prioritizing Urban Habitats for

458 Connectivity Conservation: Integrating Centrality and Ecological Metrics. Environmental

459 Management 56:664-674. DOI: 10.1007/s00267-015-0520-2.

460 R Development Core Team. 2019. R: A language and environment for statistical computing. R

461 Foundation for Statistical Computing, Vienna, Austria. https://www.R-project.org.

462 Rodríguez-Rodríguez MC, Jordano P, Valido A. 2017. Functional consequences of plant-animal

463 interactions along the mutualism-antagonism gradient. Ecology 98:1266-1276. DOI:

464 10.1002/ecy.1756.

465 Saunders ME, Rader R. 2019. Network modularity influences plant reproduction in a mosaic

466 tropical agroecosystem. Proceedings. Biological sciences 286:20190296. DOI:

467 10.1098/rspb.2019.0296.

468 Silva V, Catry FX, Fernandes PM, Rego FC, Paes P, Nunes L, Caperta AD, Sérgio C, Bugalho

469 MN. 2019. Effects of grazing on plant composition, conservation status and ecosystem services

470 of Natura 2000 shrub-grassland habitat types. Biodiversity and Conservation 28:1205-1224.

471 DOI: 10.1007/s10531-019-01718-7. 
472 Skórka P, Settele J, Woyciechowski M. 2007. Effects of management cessation on grassland 473 butterflies in southern Poland. Agriculture, Ecosystems and Environment 121:319-324. DOI: 474 10.1016/j.agee.2006.11.001.

475 Thébault E, Fontaine C. 2010. Stability of ecological communities and the architecture of 476 mutualistic and trophic networks. Science 329:853-856. DOI: 10.1126/science.1188321.

477 Thomas JA, Telfer MG, Roy DB, Preston CD, Greenwood JJD, Asher J, Fox R, Clarke RT, 478 Lawton JH. 2004. Comparative losses of British butterflies, birds, and plants and the global 479 extinction crisis. Science 303:1879-1881. DOI: 10.1126/science.1095046.

480 Thompson PL, Rayfield B, Gonzalez A. 2017. Loss of habitat and connectivity erodes species 481 diversity, ecosystem functioning, and stability in metacommunity networks. Ecography 40:98482 108. DOI: $10.1111 /$ ecog. 02558.

483 Tscharntke T, Bommarco R, Clough Y, Crist TO, Kleijn D, Rand TA, Tylianakis JM, Nouhuys S 484 van, Vidal S. 2007. Conservation biological control and enemy diversity on a landscape scale. 485 Biological Control 43:294-309. DOI: 10.1016/j.biocontrol.2007.08.006.

486 Tylianakis JM, Laliberté E, Nielsen A, Bascompte J. 2010. Conservation of species interaction 487 networks. Biological Conservation 143:2270-2279. DOI: 10.1016/j.biocon.2009.12.004.

488 Valenti R, Renzi G. 2016. Flora e fauna protetta del Friuli Venezia Giulia. Regione autonoma 489 Friuli Venezia Giulia, Trieste.

490 Villemey A, van Halder I, Ouin A, Barbaro L, Chenot J, Tessier P, Calatayud F, Martin H, 491 Roche P, Archaux F. 2015. Mosaic of grasslands and woodlands is more effective than habitat 492 connectivity to conserve butterflies in French farmland. Biological Conservation 191:206-215. 493 DOI: 10.1016/j.biocon.2015.06.030.

494 WallisDeVries MF, Ens SH. 2010. Effects of habitat quality and isolation on the colonization of 495 restored heathlands by butterflies. Restoration Ecology 18:390-398. DOI: 10.1111/j.1526496 100X.2008.00447.x.

497 WallisDeVries MF, Poschlod P, Willems JH. 2002. Challenges for the conservation of 498 calcareous grasslands in northwestern Europe: Integrating the requirements of flora and fauna.

499 Biological Conservation 104:265-273. DOI: 10.1016/S0006-3207(01)00191-4.

500 WallisDeVries MF, Raemakers I. 2001. Does extensive grazing benefit butterflies in coastal 501 dunes? Restoration Ecology 9:179-188. DOI: 10.1046/j.1526-100X.2001.009002179.x.

502 Yang Z, Algesheimer R, Tessone CJ. 2016. A comparative analysis of community detection 503 algorithms on artificial networks. Scientific Reports 6. DOI: 10.1038/srep30750. 
Figure 1

The bipartite species-habitat network.

Coloured nodes represent habitat patches, with patch code within the node (see Table S1). Black nodes represent butterfly species, with node size reflecting the number of links for each species. Grey links indicate species occurrence.

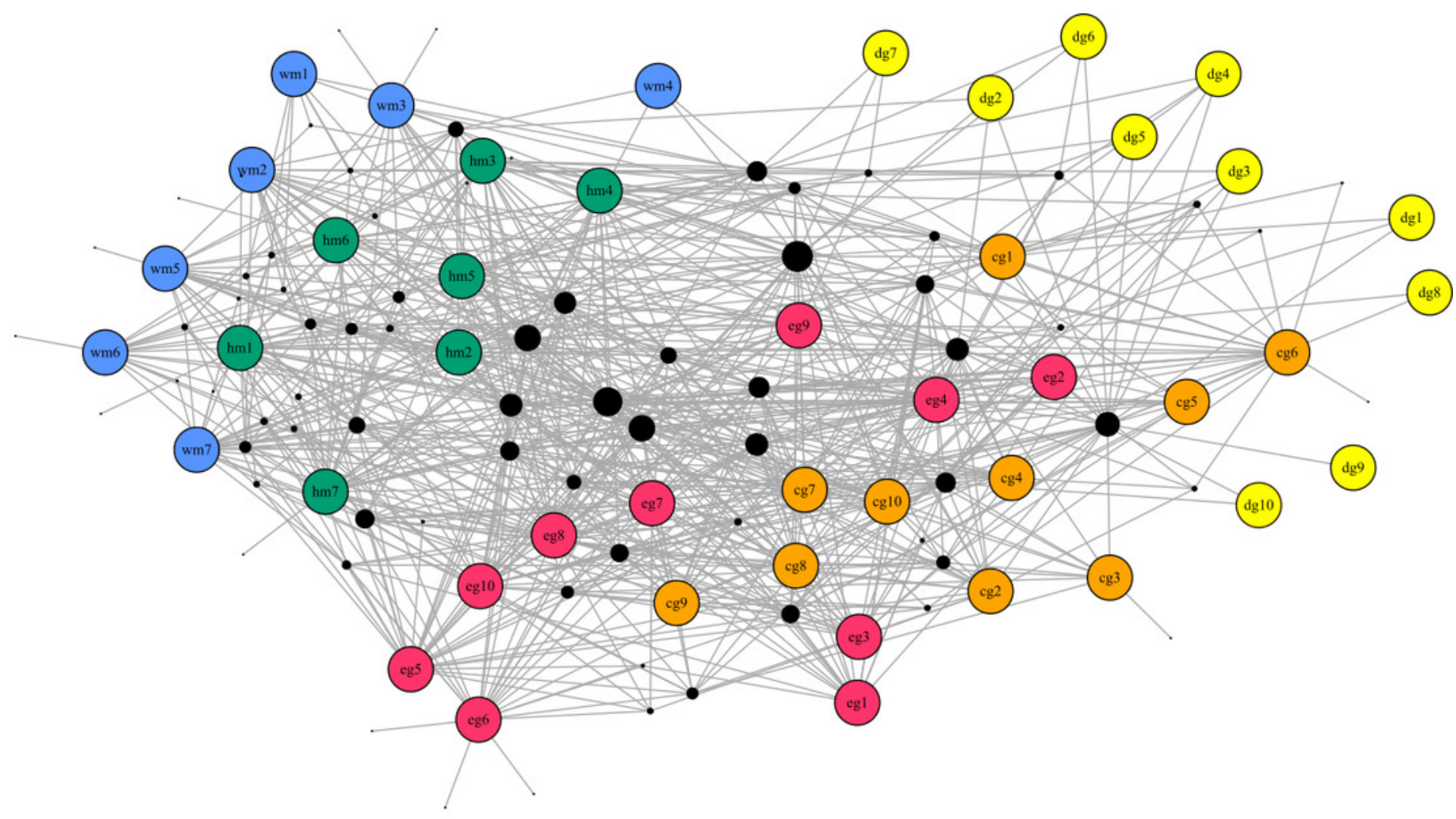

\footnotetext{
$\mathrm{dg}=$ disturbed grassland $(\mathrm{N}=10)$

$\circ \mathrm{cg}=$ continuous grassland $(\mathrm{N}=10)$

- eg $=$ evolved grassland $(N=10)$

$\mathrm{hm}=$ hay meadow $(\mathrm{N}=7)$

$w m=$ wet meadow $(N=7)$
} 


\section{Figure 2}

Community detection clusterization.

Community detection clusterization with (a) multimodel algorithm, (b) spinglass algorithm, and (c) walktrap algorithm. The different colours indicate the communities detected by the different algorithms based on the shared species, while the numbers represent the a priori habitat classification based on the vegetation physiognomy.

a

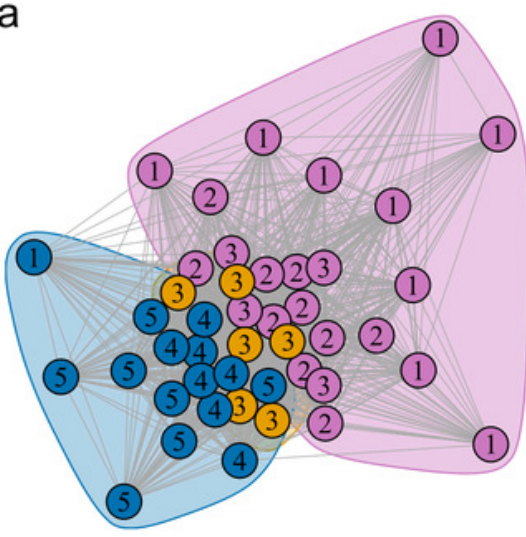

b

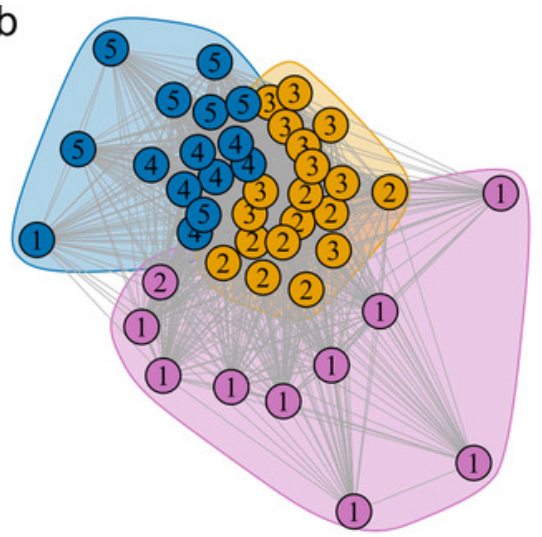

C

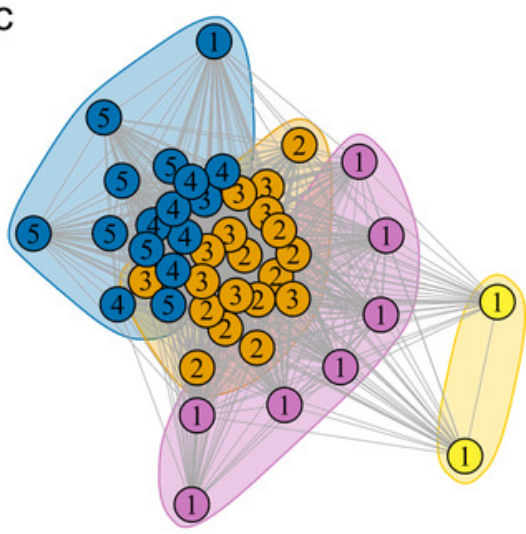

(1) disturbed grassland

(2) continuous grassland

(3) evolved grassland

(4) hay meadow

(5) wet meadow 
Figure 3

Boxplots showing the effect of habitat type on (a) species richness, (b) species evenness $\mathrm{E}_{\mathrm{var}}$, and (c) patch weighted degree centrality.

The letters $a, b, c$ indicate significant differences from Tukey's HSD test at $P<0.05$.

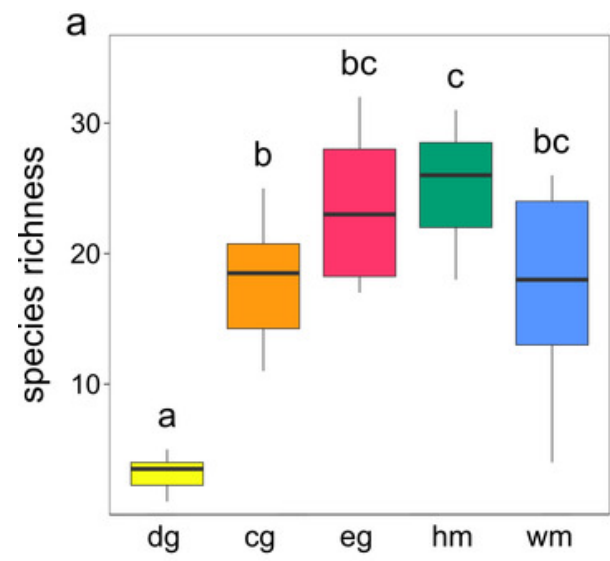

$\mathrm{dg}=$ disturbed grassland

$\mathrm{cg}=$ continuous grassland

eg = evolved grassland

O $\mathrm{hm}=$ hay meadow

$\mathrm{wm}=$ wet meadow
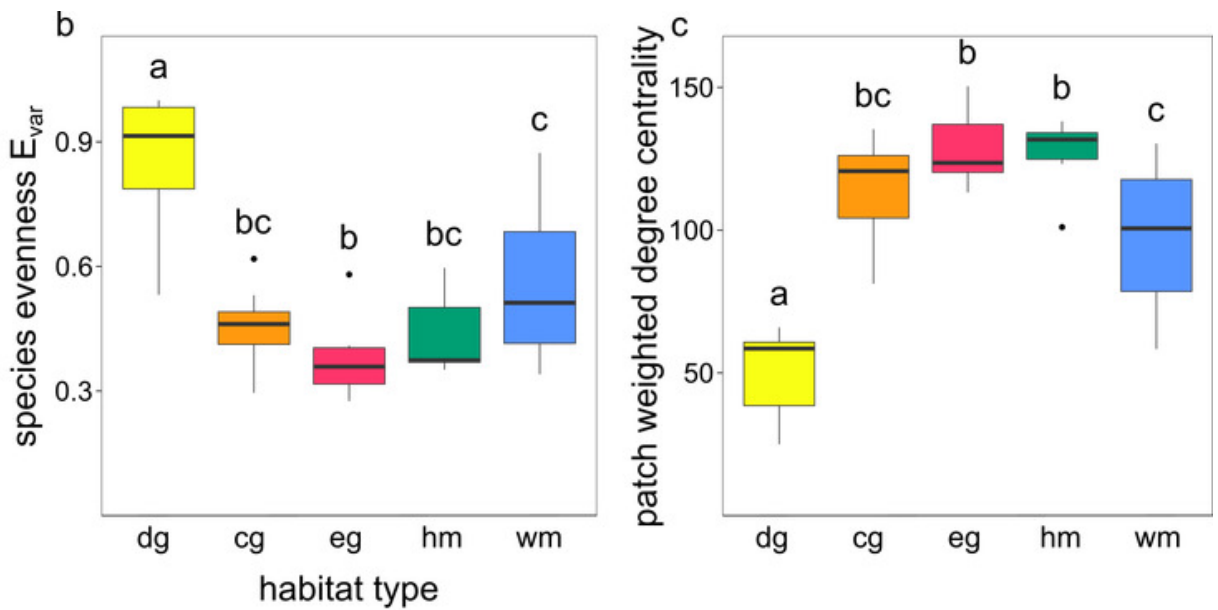
Figure 4

Weighted degree centrality.

(a) Patch ranking based on weighted degree centrality, and (b) map of the 44 sampling sites, with point size reflecting weighted degree centrality and indication of patch code (see Table $\mathrm{S} 1)$.

a

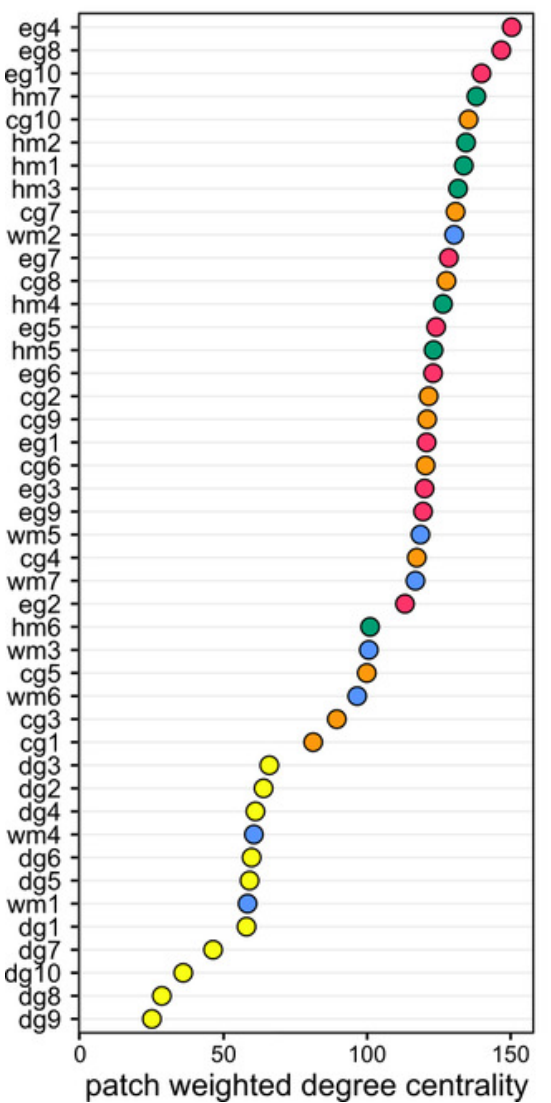

b

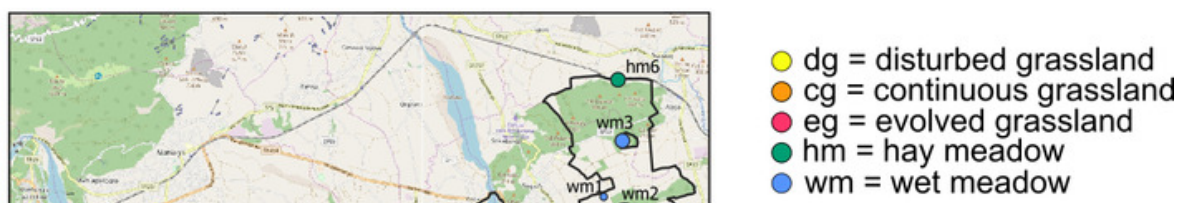




\section{Table $\mathbf{1}$ (on next page)}

Explanation and example of conservation implications of species-habitat network metrics, both at network and node level. 


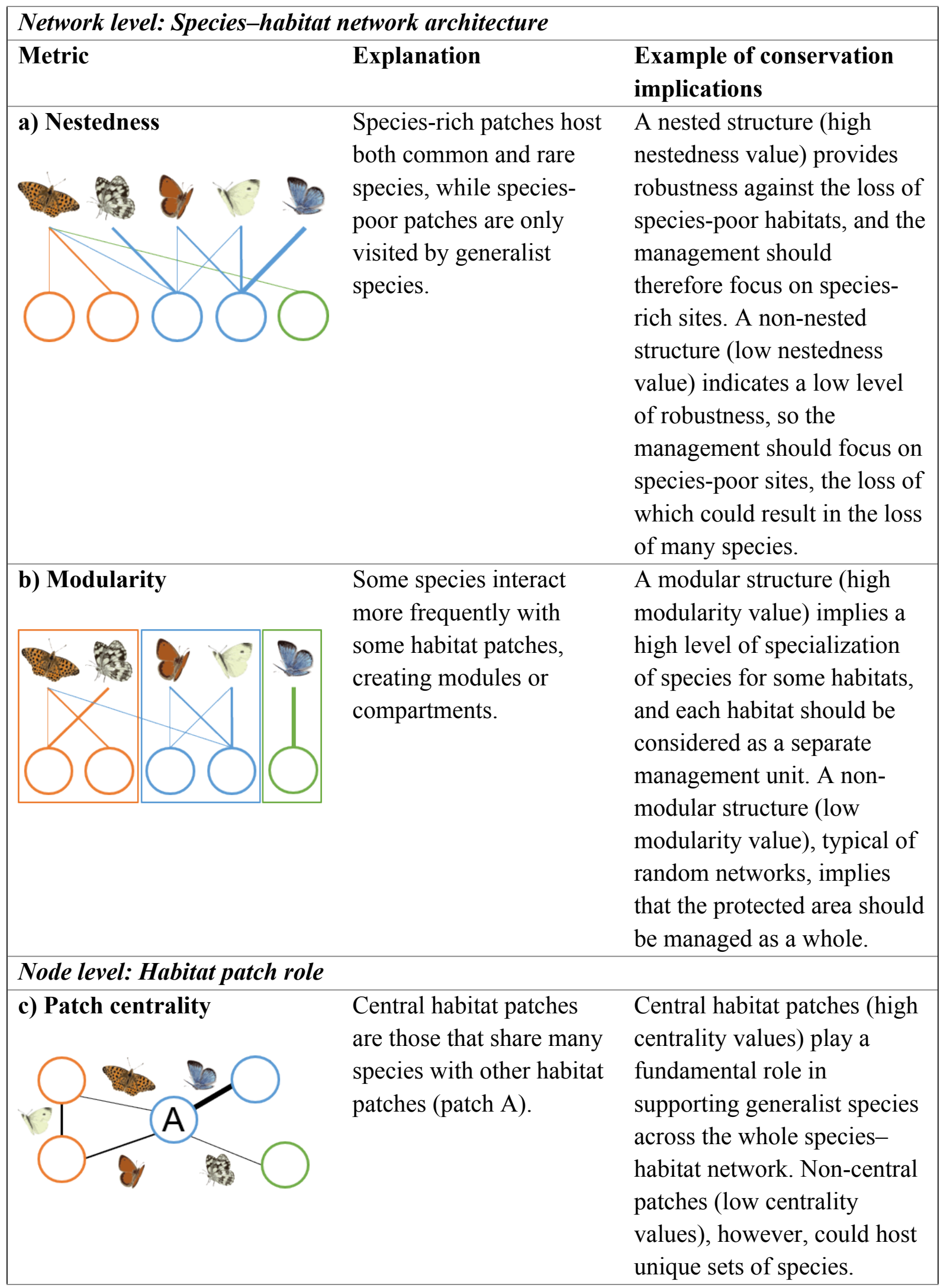




\section{Table 2 (on next page)}

Results of the linear models testing the effect of habitat type on (a) butterfly species richness, (b) butterfly species evenness $E_{\text {var }}$ and (c) patch weighted degree centrality. 


\begin{tabular}{llrrrr} 
& & Estimate & SE & t-value & p-value \\
\hline a) Species & Intercept (evolved grassland) & 23.60 & 1.64 & 14.43 & $<0.01$ \\
richness & Hay meadow & 1.54 & 2.55 & 0.61 & 0.55 \\
& Continuous grassland & -5.80 & 2.31 & -2.51 & 0.02 \\
& Disturbed grassland & -20.30 & 2.31 & -8.78 & $<0.01$ \\
& Wet meadow & -6.17 & 2.55 & -2.42 & 0.02 \\
\hline b) Species & Intercept (evolved grassland) & 0.37 & 0.04 & 8.81 & $<0.01$ \\
evenness Evar $_{\text {var }}$ & Hay meadow & 0.07 & 0.07 & 1.01 & 0.32 \\
& Continuous grassland & 0.08 & 0.06 & $1-34$ & 0.19 \\
& Disturbed grassland & 0.49 & 0.06 & 8.19 & $<0.01$ \\
& Wet meadow & 0.19 & 0.07 & 2.88 & $<0.01$ \\
\hline c) Patch & Intercept (evolved grassland) & 128.60 & 5.60 & 22.95 & $<0.01$ \\
weighted & Hay meadow & -1.66 & 8.73 & -0.19 & 0.85 \\
degree & Continuous grassland & -14.17 & 7.93 & -1.79 & 0.08 \\
centrality & Disturbed grassland & -78.27 & 7.93 & -9.88 & $<0.01$ \\
& Wet meadow & -31.21 & 8.73 & -3.57 & $<0.01$ \\
\hline
\end{tabular}

1 